\title{
Research on Grounding of Shore-to-Ship Power Supply System
}

\author{
Ningzhao Luo, Hongjiang Li, Haolan Zhang \\ College of Electric Engineering, Naval University of Engineering, Wuhan, China \\ Email: ningzhaoluo@gmail.com
}

Received December 2013

\begin{abstract}
To avoid pollution of generator exhaust port after the ship docked, the use of shore power supply is developing direction of port. And the shore power grounding method and related standards needed to be carried out. According to developing status of foreign medium voltage ship and characteristics of navy shipboard power supply, this paper presents a shore power supply network structure and its grounding method. The simulation results show the power supply network structure can effectively suppress the single-phase intermittent ground fault on the system to produce the harm.
\end{abstract}

\section{Keywords}

Medium Voltage; Grounding; Shipboard; Cold Ironing

\section{Introduction}

At present, in order to keep the high power mechanical pump, other faculties and their supply system working normally, the powerful diesel generator on shipboard must work continuously even after large-scale civil ship has docked [1]-[3], while the diesel generator produces a great mount of sulfide and nitrogen oxide because of the burning of diesel, resulting in pollution to the surroundings. International Maritime Organization (IMO) states that $\mathrm{NO}_{\mathrm{x}}$ and $\mathrm{SO}_{\mathrm{x}}$ are the main pollutions. Ships motivated by diesel put 10 million tons of $\mathrm{NO}_{\mathrm{x}}$ and 8.5 million tons of $\mathrm{SO}_{\mathrm{x}}$ into the atmosphere per year in the whole world. And the pollution substances may spread over $1000 \mathrm{~km}$ away. As the rapid development of civil marine, waste materials emitted by ships bring huge pressure to pollution controlling [4]-[6]. The ports eagerly call up civil ships to shut down donkey generator and use shore power supply. At the same time, from the angle of economy and maintenance of equipment, the supply of shore power is also needed when the navy ships are docking in the base. Meanwhile, the service of the ship with a medium voltage shipboard system brings a whole new challenge to shore power system. No matter in civil field or military field, the research of medium voltage shore power system has just started without standard reference. The exploration of shore power supply network structure and its grounding method, as well as related standards are becoming a hot issue among the world ship power field [7] [8].

This paper deeply discusses the shore power supply network structure and its grounding method, provides a theoretical basis of shore power supply standards. 


\section{Civil Ship Medium Voltage Shore Power System Grounding Method}

Civil shore power supply system grounding protection expert Dev Paul P.E drew this conclusion after aged research [9]:

Shore power supply system has excessive distributed capacitances, so the ground-free method should not be used. According to industry standards, if the ground capacitance current is over $10 \mathrm{~A}$, the grounding system should be low resistance grounding. However, because the distributed capacitance varies with the number of docked ships, the low resistance grounding method should be used even though the ground capacitance current is below $10 \mathrm{~A}$. For the sake of reducing the stray current, it is necessary to measure the resistance between the grounding device and ship shell. And an independent connection between the ground and ship shell is needed, in case of the excessive resistance [10].

To prevent an open circuit or short circuit, the grounding device should be watched at all time, otherwise a disaster may happen.

\section{Military Ship Shore Power System Grounding Method}

It is very common that military ships are supplied by shore power system when docking. Generally, Shore power is neutral-point grounding. While the shore power is supplying, the shore neutral-point of power transformer directly connects to ground, facilities on the ship are connected to earth through the ship hull and sea eater, using as grounding protection. In the case of multi-ship docking, every ship shore power cable is connected to different connection spot of a same transformer in parallel. Figure $\mathbf{1}$ is a typical shore power system for low voltage ship for now.

When the system voltage level reaches $6 \mathrm{kv}$, the previous shore power system structure is no longer suitable. Direct grounding of the transformer neutral-point may cause fault current and step-voltage, threatening the safety of people on the port.

\section{Design of Shore Power Supply Network Structure and Grounding Method Applied to Military Naval Port}

According to the conclusion from Dev Paul P.E, although the high resistance grounding method has advantages, the shore power transformer is not suitable for high resistance grounding as the ship is. It is because that while ships are docked in port and supplied in parallel, the overall capacitance is too high due to the superposition effect of each ship's grounding capacitance. Furthermore, the number of docked ships is changing all the time, high resistance grounding method needs to be frequently adjusted.

After the docking, sailors still work and live in ship, the shore power cable could be easily damaged when dragging, and meanwhile, the risk of single-phase grounding exists when doing some maintaining work. When using the low resistance grounding method, if there is a malfunction, the ship would lose its power and influence normal work. Besides, low resistance method causes very high current when a failure happen, it would destroy facilities and produce powerful electric arc which brings harm to the workers around. So a shore power network and grounding method must be designed to fulfill the requirement of docked ships with medium voltage system.

There is a regulation about military ship: "The design of power system should ensure the continuity of power supply under all kinds of working conditions”. The grounding method that can attain such requirement is high resistance grounding and resonance grounding.

Shore power line is relatively short, the cable part of it can be regarded as aerial cable, and its grounding capacitance is low. Grounding capacitance of aerial cable is between $0.0055 \mu \mathrm{F} / \mathrm{km}-0.003 \mu \mathrm{F} / \mathrm{km}$. So shore power system is available for high resistance grounding method which is economic and simply. This paper aims at the characteristics of large ship and designs a flexible shore power supply network structure. Figure 2 is an

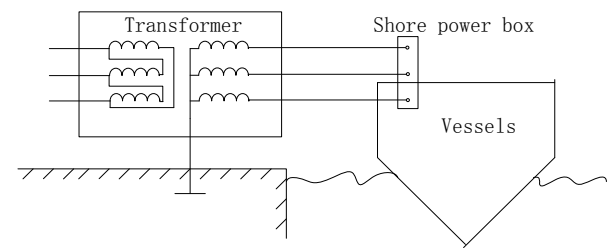

Figure 1. Low voltage shore power system. 


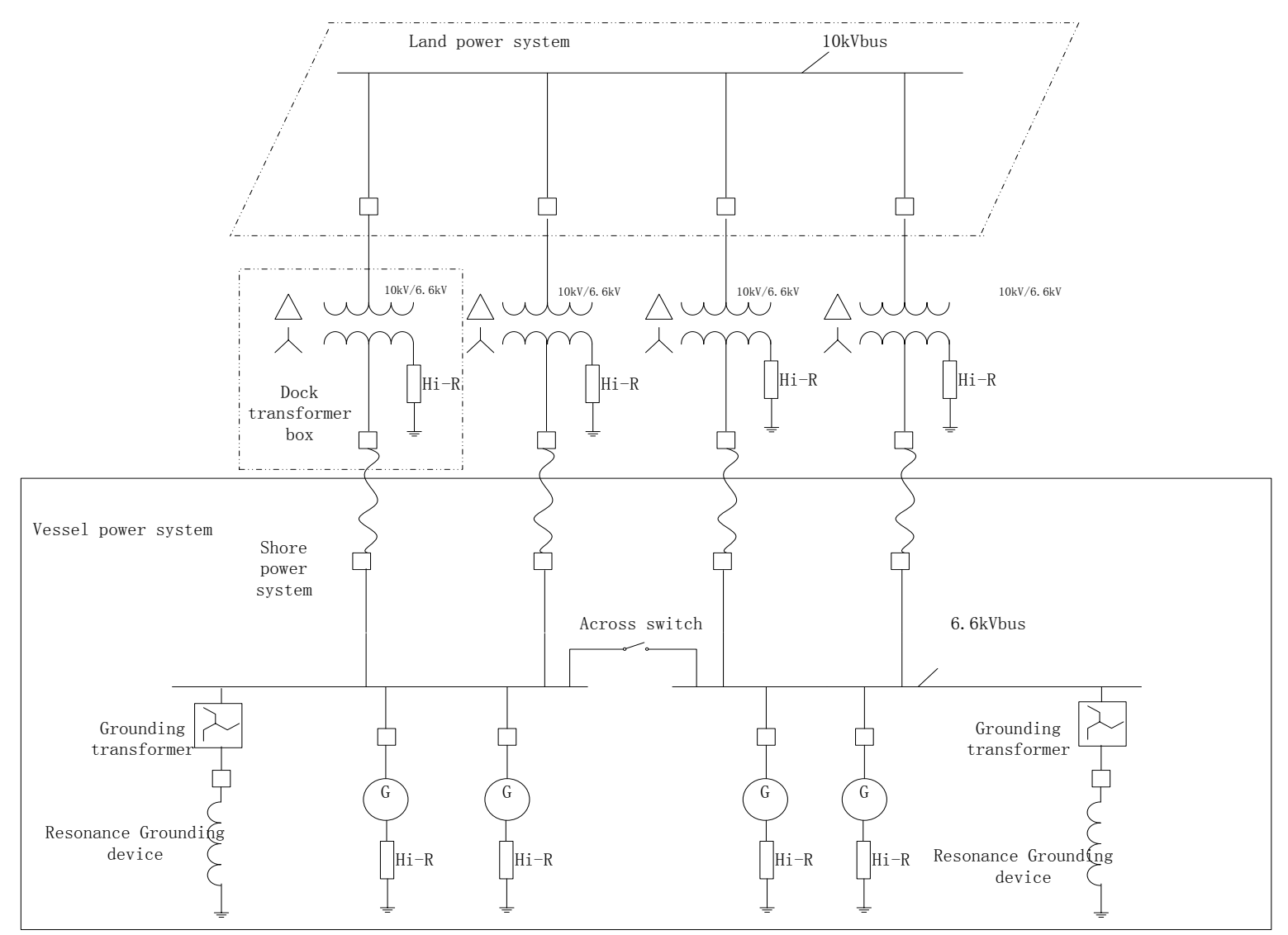

Figure 2. Shore power system structural drawing.

electric blueprint. This kind of system has these characteristics below:

1) Large ship is supplied by shore power sectionally becacue its large power capacity, therefore, the number of landing distribution box should be 2 to 4, in order to fulfill different demand of different ship type. Futhermore, outputs of transformer should not be connected in parallel, preventing from the circulation current.

2) Transformer in land electric box is $\Delta / Y$ connection, the secondary side of the transformer is high resistance grounding, making itself isolated from the primary side. This connection creates good situation where many ships are docking, because if the electric box has not configured independent isolation transformer inside but outputs through the same transformer, the grounding capacitance of all ships would be connected in parallel, the maximum of failure current would be above the allowance current with high resistance grounding method.

3) In terms of medium voltage ship with excessive grounding capacitance, the resonance grounding device should be operated when the shore power system is working, making up for excessive capacitance current and providing effective grounding protection for shipboard power system.

4) Secondary side of isolation transformer values $400 \Omega-500 \Omega$, making the grounding parameters consistent in both shore power system and shore power system.

5) The output switch of generator is breaking while the shore power system is working, making the neutral-point grounding device of generator isolated from the electric network.

\section{Grounding Fault Simulation of Shore Power System}

Because of the application of isolation transformer, the fault condition from shore power and the shipboard power is nearly the same. The grounding fault coming from the broken shore power cable is simulated. Fault electric arc is continuously burning between the A phase and ground, burning time is the bottom of every negative period and the arc extinguishes after half period. Nominal voltage is $6.3 \mathrm{kv}$ and resistance of electric arc is $0.1 \Omega$. The results are shown below in Figure 3. 


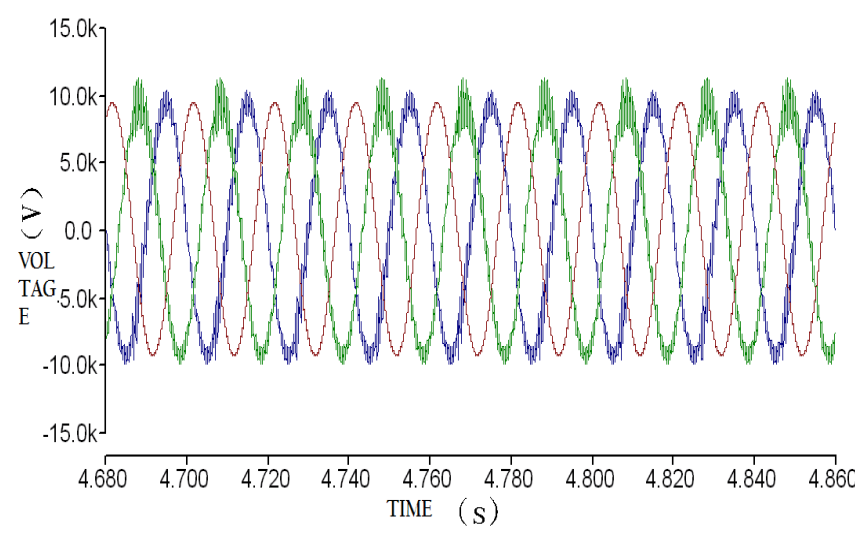

Figure 3. Secondary of isolation transformer simulated waveform.

Figure 3 gives us the secondary side of isolation transformer simulated waveform. We can figure out that if the grounding device is properly configured, the grounding fault coming from shore power cable has little influence on power quality.

\section{Conclusion}

In order to keep the military shore power system safe and stable, multiple isolation transformers should be set up in port. And the secondary neutral-points of isolation transformer should be connected to ground through high resistance device, preventing the overvoltage produced by grounding arc re-burning fault. This kind of shore power supply network can keep the setting of protection device consistent in both shore power and shipboard power system, besides, it has upstanding continuity in power supply, and furthermore, it is less affected by the change of distributed capacitance, so this shore power grounding method is suitable for military port.

\section{References}

[1] Li, H.H. (2011) Research on Large Ship at Port Using Shore Electricity. Shanghai Shipbuilding, 2, 53-64.

[2] Cui, Y.X. and Sun, Y.T. (2012) Research on High-Voltage Shore-to-Ship Power Supply and Its Key Technology. Port Operation, 1, 28-31.

[3] Zhou, Z.N. (2007) Brief Introduction of Ship’s Connection to Shore Electricity. Ship Design Transactions, 2, 64-66.

[4] Zheng, Y.G. (2010) Discussion of Port Using Shore Electricity System Design. Construction Electricity, 1, 15-20.

[5] Sun, H.X. (2000) Fitness Design of Vessel Shore Electricity Connection Circuit. Ship Electricity Technology, 3, 1-3.

[6] Tan, Y.X. (2010) The Implement of Shore Electricity in China. World Maritime Transportation, 9, 56-59.

[7] Zhang, Y.H. (2010) Discussion of Shore Electricity on Current Level of China. China Water Carriage, 9, 22-23.

[8] Miao, F.J. (2007) Shore Electricity Research on Preventing Pollution of Arrived Ship. Shanghai Maritime University, Shanghai, 12-21.

[9] Dev Paul, P.E. A Closer Look at the Grounding of Shore-to-Ship Power Supply System. The 2009 Industrial and Commercial Power Systems Technical Conference, Denver.

[10] Jia, S.Y. (2009) Research on Emission of Greenhouse Gases Regarding Ship at Port Using Shore Electricity. Dalian Maritime University, Dalian, 56-61. 